
logical variables in South Korea for the period 1999-2010

\title{
J. Seo et al.
}

Correspondence to: D. Youn (dyoun@chungbuk.ac.kr) 
(a) Power spectra of $\left[\mathrm{O}_{3}\right]$ and $\mathrm{KZ}_{29,3}\left[\mathrm{O}_{3}\right]$

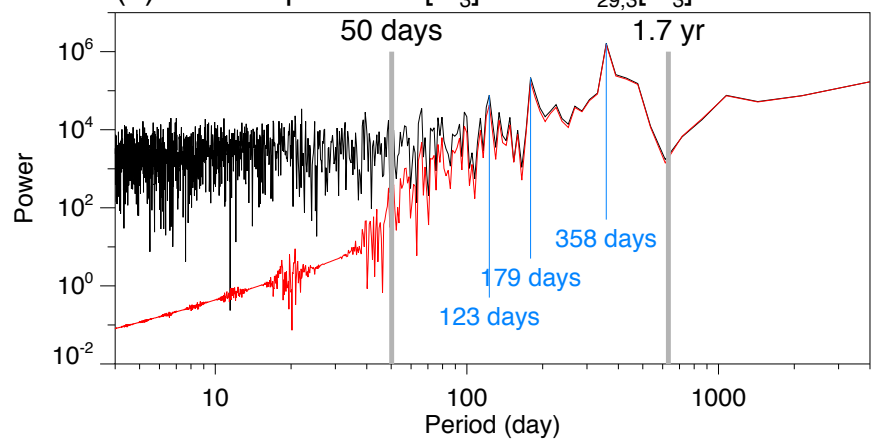

(b) Power spectra of $\mathrm{SI}$ and $\mathrm{KZ}_{29,3} \mathrm{SI}$

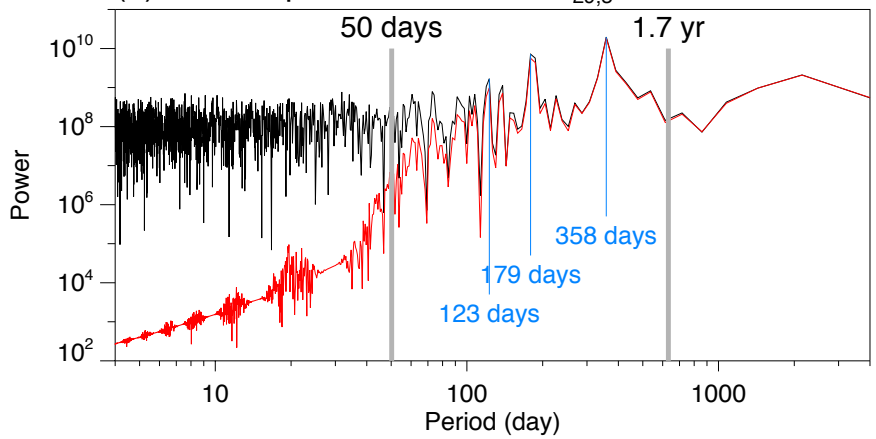

(c) Power spectra of $\mathrm{T}_{\max }$ and $\mathrm{KZ} \mathrm{Z}_{29,3} \mathrm{~T}_{\max }$

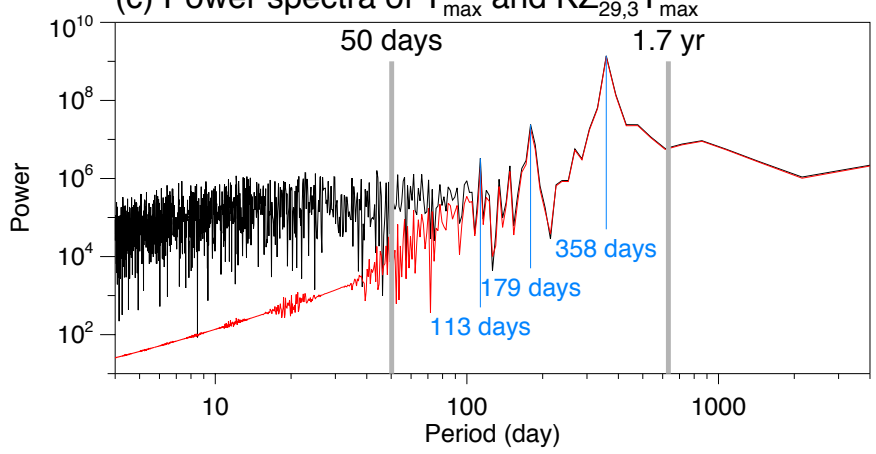

Figure S1. Power spectra of (a) log-transformed $\mathrm{O}_{3}$ 8h time series $\left(\left[\mathrm{O}_{3}\right]\right)$ and its baseline $\left(\mathrm{KZ}_{29,3}\left[\mathrm{O}_{3}\right]\right)$ at the City Hall of Seoul, (b) daily average surface insolation (SI) and its baseline $\left(\mathrm{KZ}_{29,3} \mathrm{SI}\right)$, and (c) daily maximum temperature $\left(T_{\max }\right)$ and its baseline $\left(\mathrm{KZ}_{29,3} T_{\max }\right)$ observed at the weather station in Seoul for the period 1999-2000. Each power spectra of original time series and its baseline obtained by $\mathrm{KZ}_{29,3}$ filter are represented as black and red lines, respectively. 
(a) Baseline $\left(\left[\mathrm{O}_{3 \mathrm{BL}}\right]\right)$

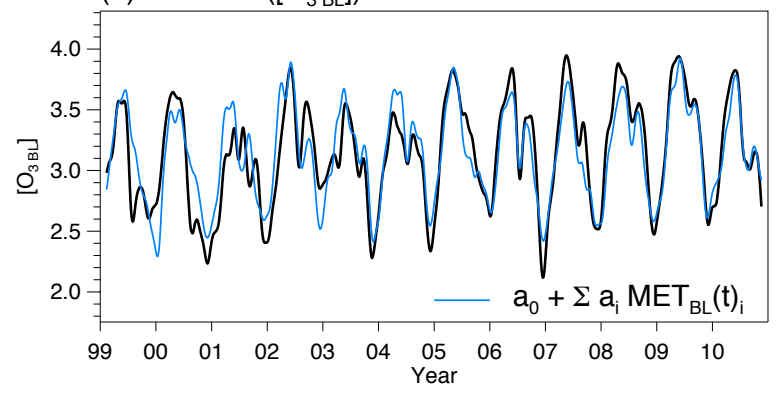

(c) $\delta(t)=\varepsilon(t)-\left[O_{3 L T}\right]$

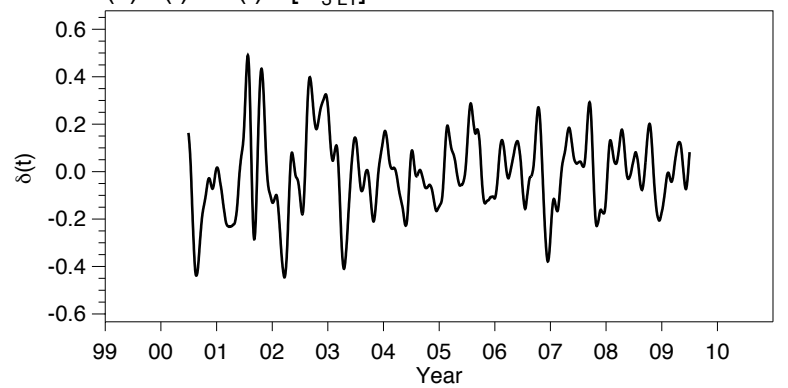

(e) Autocorrelation of $\delta(t)$

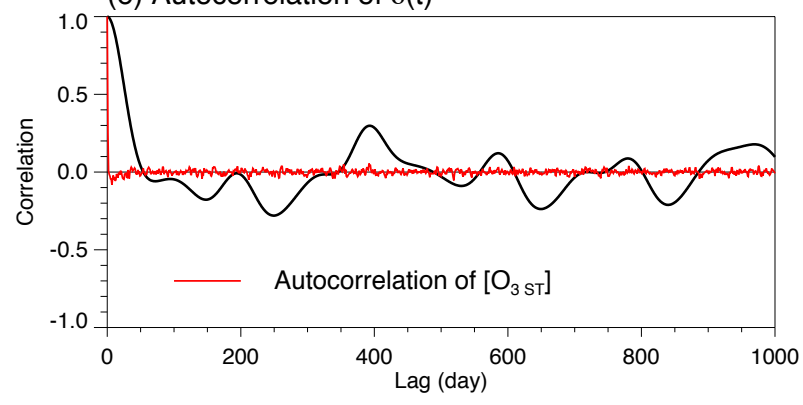

(b) $\varepsilon(t)=\left[\mathrm{O}_{3 \mathrm{BL}}\right]-\left[\mathrm{a}_{0}+\Sigma \mathrm{a}_{\mathrm{i}} \operatorname{MET}_{\mathrm{BL}}(\mathrm{t})_{\mathrm{i}}\right]$

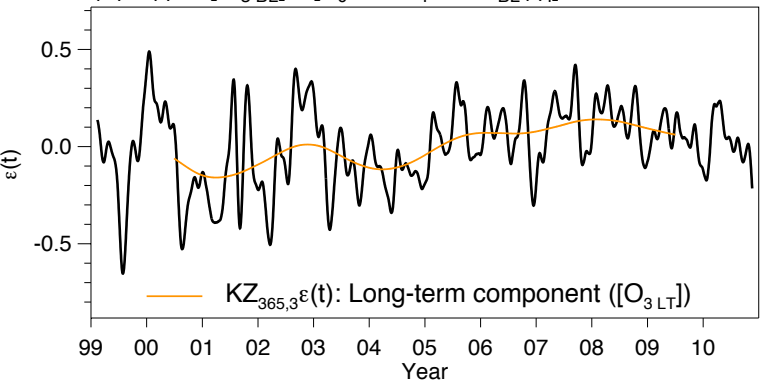

(d) Power spectrum of $\delta(t)$

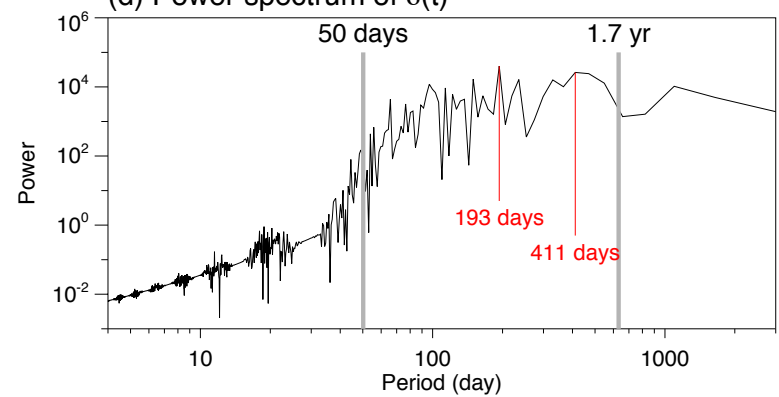

Figure S2. Time series of (a) baseline of log-transformed $\mathrm{O}_{3}{ }_{8 \mathrm{~h}}\left(\left[\mathrm{O}_{3} \mathrm{BL}\right]\right)$ and combined meteorological variables regressed on the baseline $\left(a_{0}+\sum_{i} a_{i} \operatorname{MET}_{\mathrm{BL}}(t)_{i}\right)$, (b) $\varepsilon(t)$ and longterm component $\left(\left[\mathrm{O}_{3 \mathrm{LT}}\right]\right)$, and (c) $\delta(t)$ at the City Hall of Seoul. (d) Power spectrum of $\delta(t)$. (e) Autocorrelation of $\delta(t)$ and short-term component $\left(\left[\mathrm{O}_{3 \mathrm{ST}}\right]\right)$. 
(a) $\mathrm{NO}_{x}$ emissions

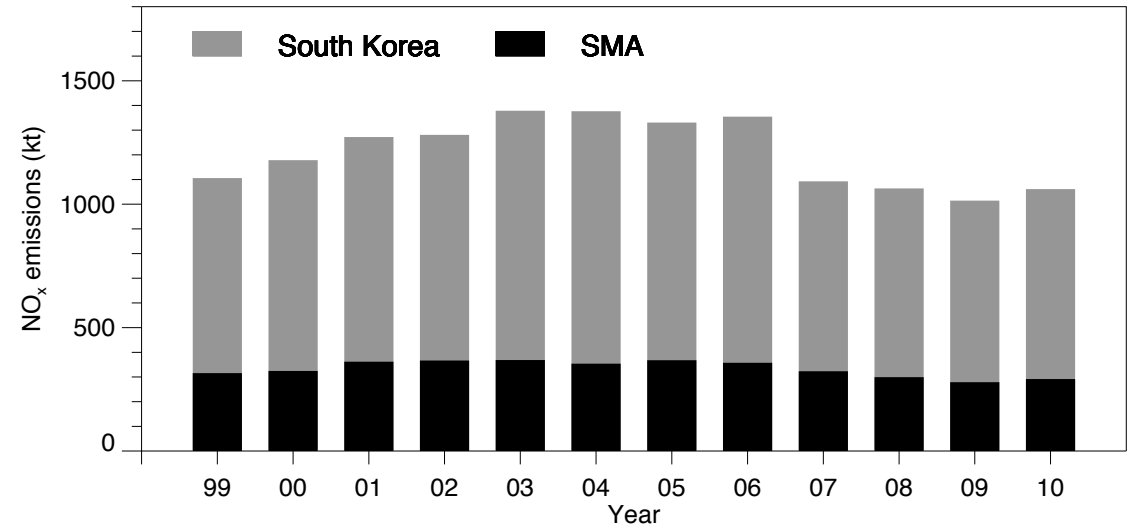

(b) VOCs emissions

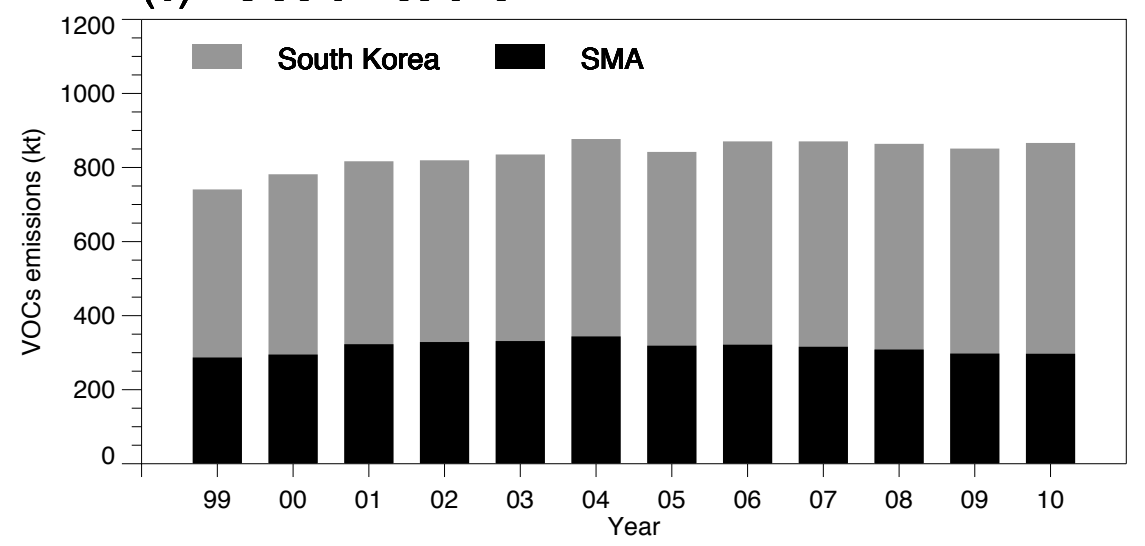

Figure S3. Total anthropogenic emissions of (a) NOx and (b) VOCs in the SMA and in South Korea (KMOE, 2013). It should be noted that the rapid decrease in $\mathrm{NO}_{x}$ emissions between the years 2006 and 2007 mainly results from applying different assessment method to the $\mathrm{NO}_{x}$ emissions from the energy industry before and after 2007. 
(a) $T_{\max B L}$ and $\left[\mathrm{O}_{3 \mathrm{BL}}\right]$ (DJF)

(b) $\mathrm{T}_{\max B L}$ and $\left[\mathrm{O}_{3 \mathrm{BL}}\right]$ (MAM)

(c) $\mathrm{T}_{\max B L}$ and $\left[\mathrm{O}_{3 \mathrm{BL}}\right]$ (JJA)

(d) $\mathrm{T}_{\max B L}$ and $\left[\mathrm{O}_{3 \mathrm{BL}}\right](\mathrm{SON})$
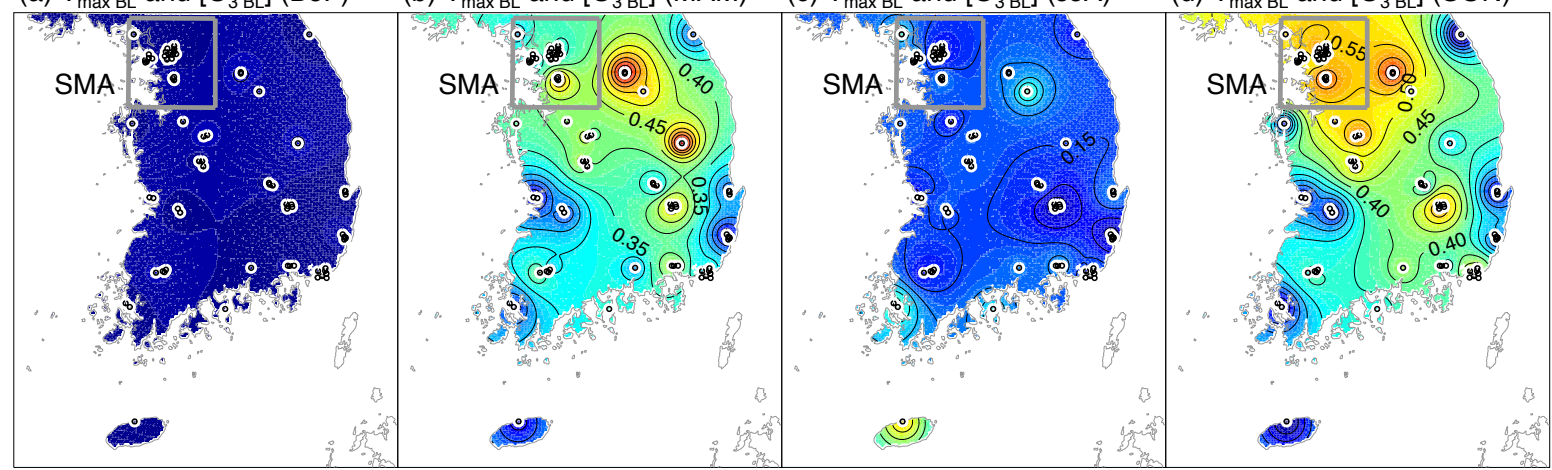

(e) $\mathrm{SI}_{\mathrm{BL}}$ and $\left[\mathrm{O}_{3 \mathrm{BL}}\right]$ (DJF)

(f) $\mathrm{SI}_{\mathrm{BL}}$ and $\left[\mathrm{O}_{3 \mathrm{BL}}\right]$ (MAM)

(g) $\mathrm{SI}_{\mathrm{BL}}$ and $\left[\mathrm{O}_{3 \mathrm{BL}}\right]$ (JJA)

(h) $\mathrm{SI}_{\mathrm{BL}}$ and $\left[\mathrm{O}_{3 \mathrm{BL}}\right]$ (SON)

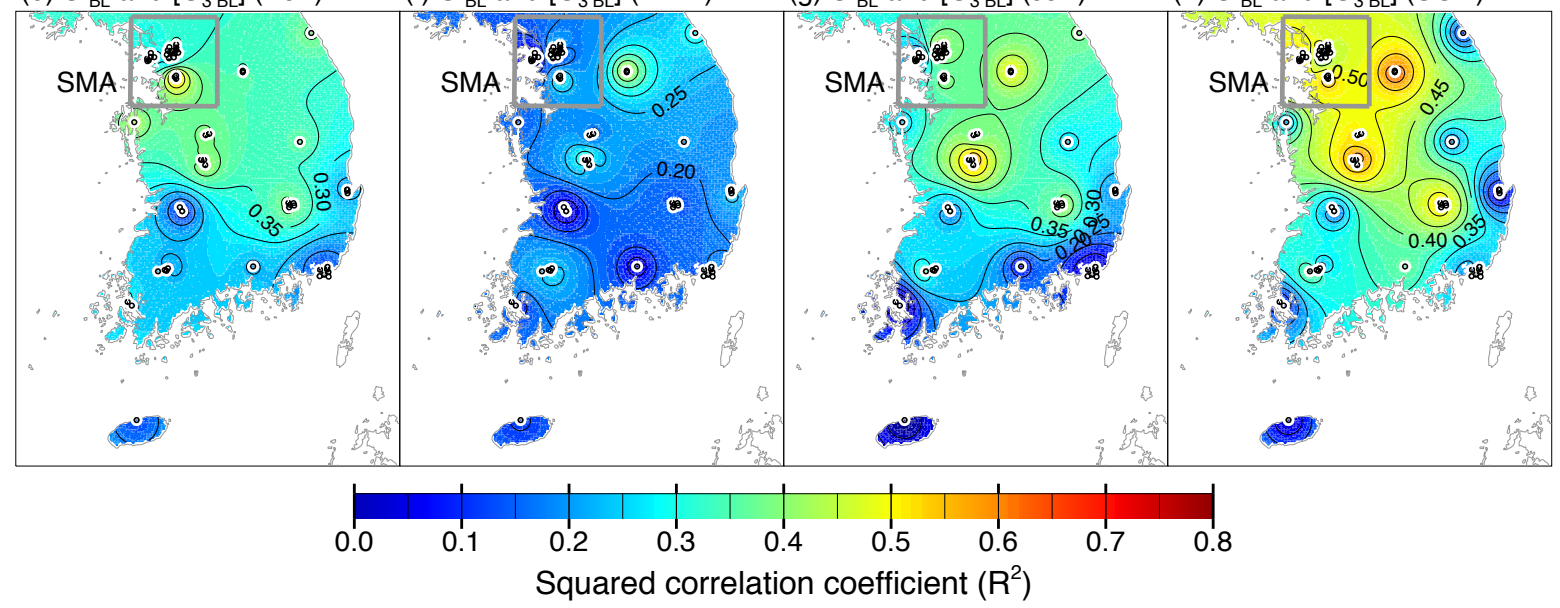

Figure S4. Spatial distributions of $R^{2}$ between baselines of $\mathrm{O}_{38 \mathrm{~h}}\left(\left[\mathrm{O}_{3 \mathrm{BL}}\right]\right)$ and daily maximum temperature $\left(T_{\max B L}\right)$ in (a) winter, (b) spring, (c) summer, and (d) autumn, and $R^{2}$ between $\left[\mathrm{O}_{3 \mathrm{BL}}\right]$ and daily average insolation $\left(\mathrm{SI}_{\mathrm{BL}}\right)$ during (e) winter, (f) spring, (g) summer, and (h) autumn for the period 1999-2010. 


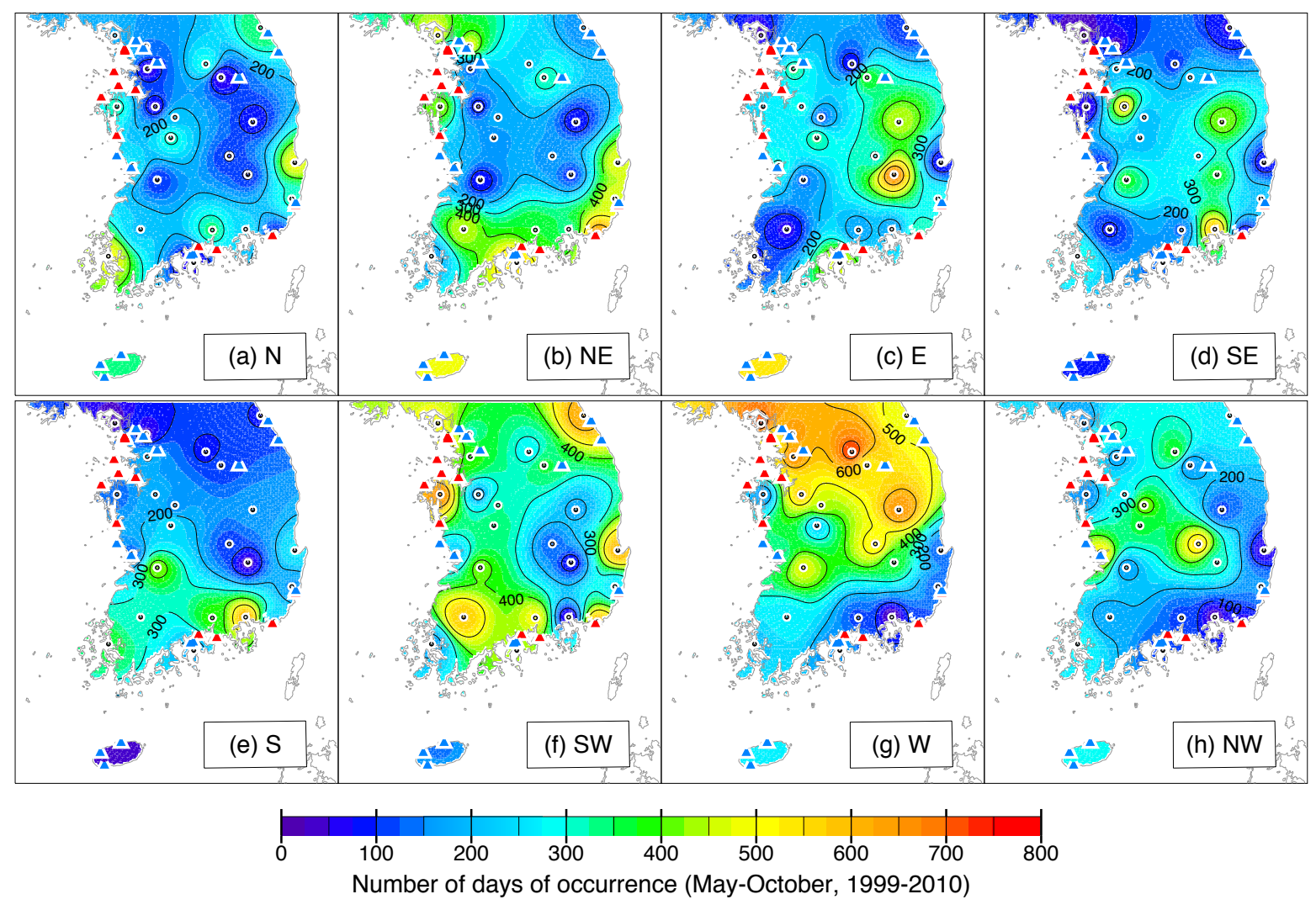

Figure S5. Spatial distributions of number of days in each wind direction (WD) during the months of frequent high $\mathrm{O}_{3}$ events (May-October) for the period 1999-2010. 
(a) $\left[\mathrm{O}_{3 \text { SEASON }}\right]$ mode 1

(b) $\left[\mathrm{NO}_{2 \text { SEASON }}\right]$ mode 1

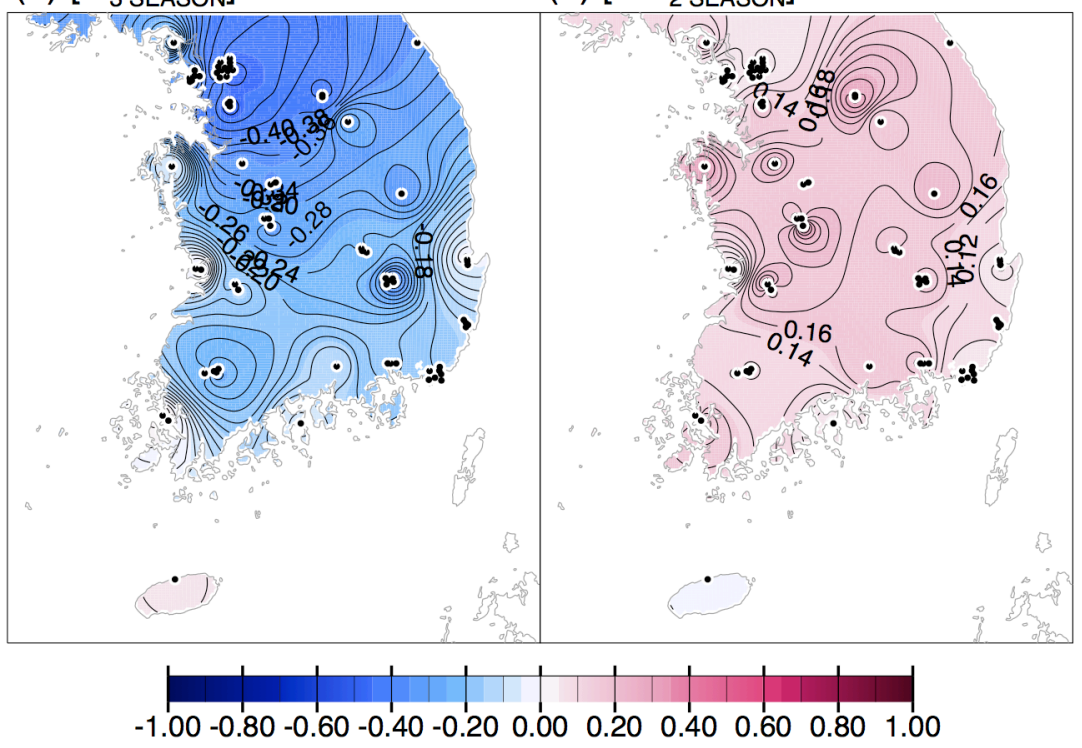

(c) Time series mode 1 (SCF: $94.3 \%, R=0.56$ )

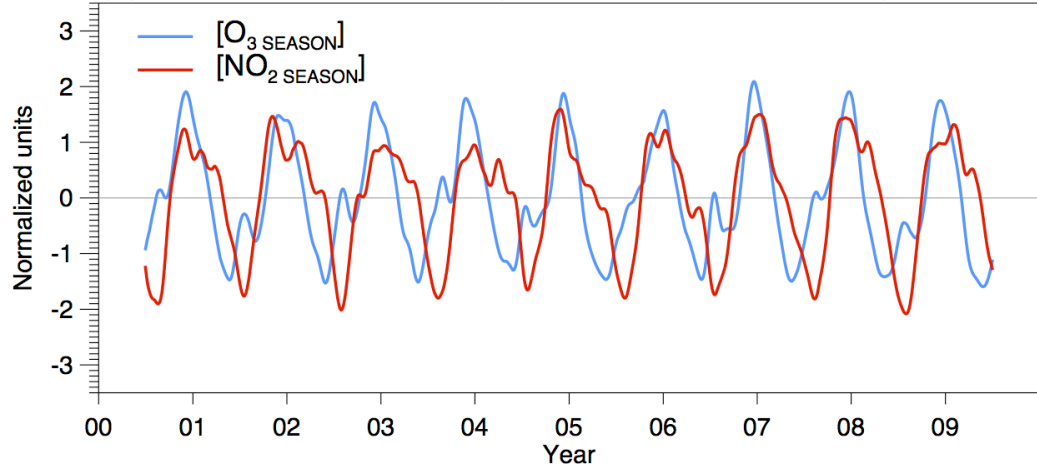

Figure S6. The first leading mode of SVD between the seasonal components of (a) daily maximum 8 -h average $\mathrm{O}_{3}\left(\left[\mathrm{O}_{3}\right.\right.$ SEASON $\left.]\right)$ and (b) daily average $\mathrm{NO}_{2}\left(\left[\mathrm{NO}_{2}\right.\right.$ SEASON $\left.]\right)$ with (c) time series of the SVD expansion coefficient associated with $\left[\mathrm{O}_{3}\right.$ SEASON] mode (blue line) and $\left[\mathrm{NO}_{2}\right.$ SEASON] mode (red line). 
(a) $\left[\mathrm{O}_{3 \mathrm{ST}}\right]$ mode 1

(b) $\left[\mathrm{NO}_{2 \mathrm{ST}}\right]$ mode 1

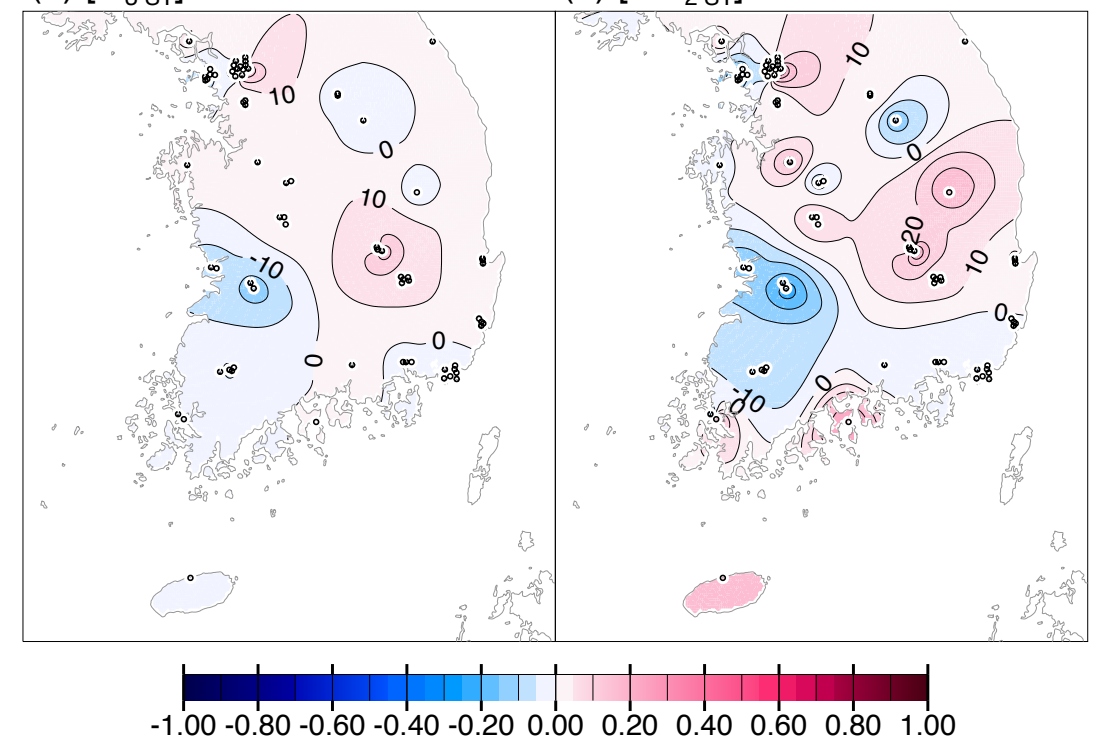

(c) Time series mode 1 (SCF: $16.3 \%, R=0.58$ )

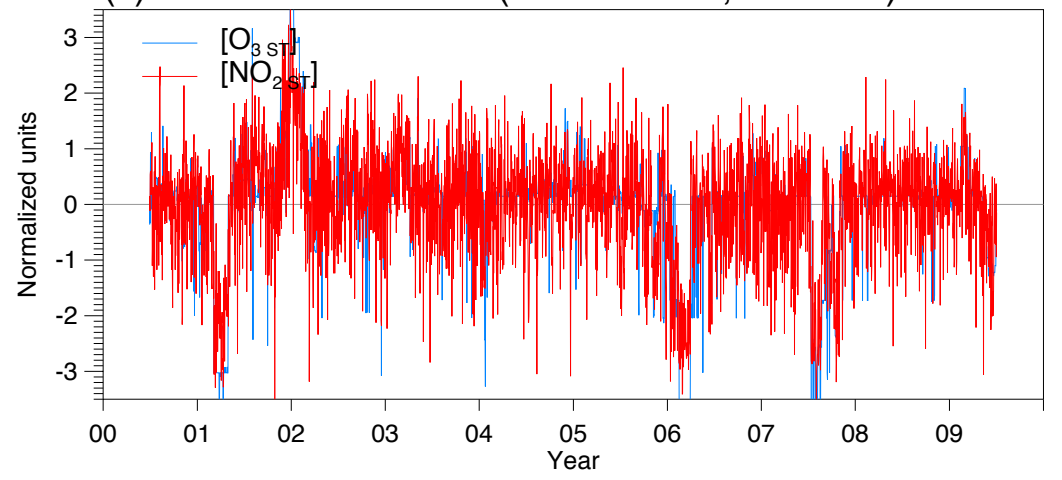

Figure S7. The first leading mode of SVD between the short-term components of (a) daily maximum 8-h average $\mathrm{O}_{3}\left(\left[\mathrm{O}_{3} \mathrm{sT}\right]\right)$ and (b) daily average $\mathrm{NO}_{2}\left(\left[\mathrm{NO}_{2} \mathrm{sT}\right]\right)$ with (c) time series of the SVD expansion coefficient associated with $\left[\mathrm{O}_{3} \mathrm{sT}\right]$ mode (blue line) and $\left[\mathrm{NO}_{2} \mathrm{ST}\right]$ mode (red line). 
(a) $\left[\mathrm{O}_{3 \mathrm{ST}}\right]$ mode 2

(b) $\left[\mathrm{NO}_{2 \mathrm{ST}}\right]$ mode 2

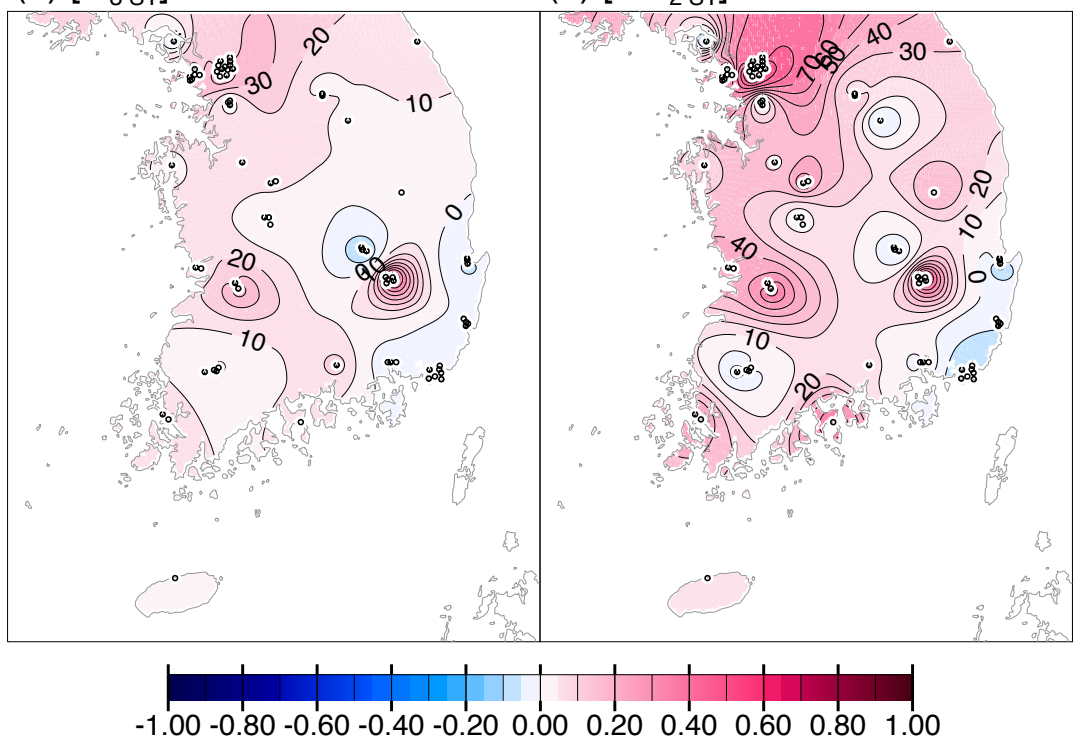

(c) Time series mode 2 (SCF: $13.1 \%, \mathrm{R}=0.53$ )

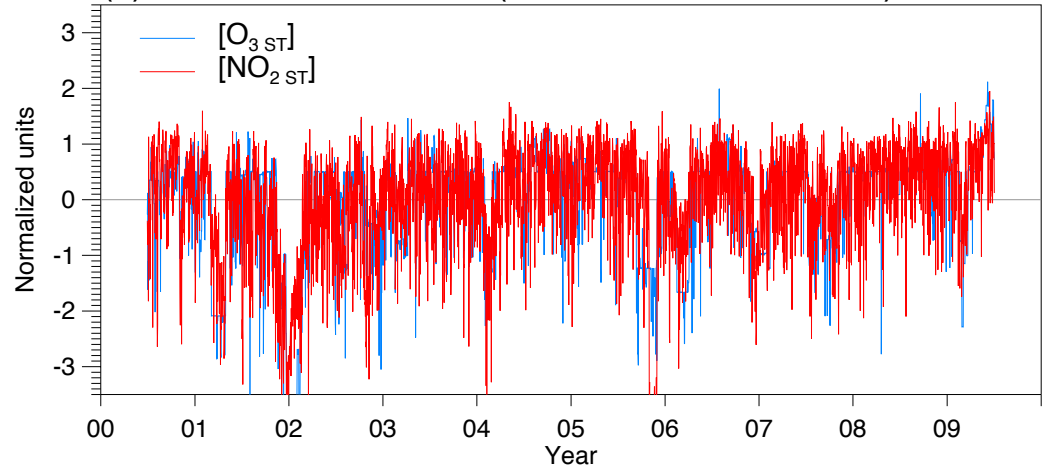

Figure S8. The second mode of SVD between the short-term components of (a) daily maximum 8-h average $\mathrm{O}_{3}\left(\left[\mathrm{O}_{3} \mathrm{sT}\right]\right)$ and (b) daily average $\mathrm{NO}_{2}\left(\left[\mathrm{NO}_{2} \mathrm{sT}\right]\right)$ with (c) time series of the SVD expansion coefficient associated with $\left[\mathrm{O}_{3} \mathrm{ST}\right]$ mode (blue line) and $\left[\mathrm{NO}_{2} \mathrm{ST}\right]$ mode (red line). 